\title{
A cross sectional study of socio-demographic factors, crime characteristics and psychiatric morbidity in violent offenders
}

\author{
Anitha Rayirala ${ }^{1}$, K. Sudha Rani2,,", Divija Bunga ${ }^{3}$, Umashankar ${ }^{4}$ \\ ${ }^{1,2}$ Associate Professor, ${ }^{3}$ Post Graduate, ${ }^{4}$ Professor, Dept. of Psychiatry, ${ }^{1}$ Rajiv Gandhi Institute of Medical Sciences, Adilabad, Telangana, \\ ${ }^{2-4}$ Institute of Mental Health, Osmania Medical College, Hyderabad, Telangana, India \\ *Corresponding Author: K. Sudha Rani \\ Email: sudhaimh@gmail.com
}

\begin{abstract}
Introduction: Homicide and attempt to murder are unique and serious violent offences. These serious offences have a huge impact on society. But there are a very few studies available in India to understand the psychiatric morbidity and the profile of these offenders. Hence the need for present study.

Aim: To study the various socio-demographic factors, crime characteristics and psychiatric morbidity in violent offenders.

Materials and Methods: It is a cross sectional study conducted at the central prison, Hyderabad. Study sample includes 60 violent offenders involved in serious crimes like murder (IPC SEC 302), attempt to murder (IPC SEC 307) and others.

Results and Conclusions: Although certain characteristics stood out, it is important to note that violent crime is multi-factorial, complex and embraces several theories. With that stated, the purpose of this study was mainly to be able to produce one or more profiles of offenders convicted of murder, attempted murder, in Telangana. The common profile which emerged was persons of young age, low education, married, low socio economic status, and rural background, unemployed with no criminal background, committed crime under intoxication, perpetrated due to provocation by other person and impulsive due to domestic reasons. It is remarkable to know that no one had other psychiatric disorders apart from substance dependence and intoxication at the time of commission of crime.

So more awareness programs and campaigns regarding influence of alcohol on the crimes, can be conducted with the help of Police, Government, Private organisations and media, especially in vulnerable and at risk population for crime, which would indirectly decrease alcohol intake in the vulnerable population and decrease crime rate.
\end{abstract}

Keywords: Crime, Prisoners, Violence, Offenders, Victims, Psychopathology.

\section{Introduction}

Homicide and attempt to murder are unique and serious violent offences. These serious offences have a huge impact on society. Violent crimes are violations of criminal law that involve the intentional use of violence by one person against another. According to National Research Council "Violent behaviours are those behaviours that intentionally threaten, attempt, or inflict physical harm on others like homicide, assault, robbery, rape etc. ${ }^{1}$ Among violent offences, murder and attempt to murder are found to be more common and violent offenders appear to be a distinct and specific population. In Telangana region, the total number of violent crimes were found to be 8004 with murders accounting to 1046 and the common reasons reported by Crime Records Bureau 2016 being personal enmity, property disputes, illicit relationships, love affairs, water or money disputes, naxalism, robbery, rape, suspicion of witch craft etc but only 6 murders were due to mental illness. Whereas in neighboring state of Andhra Pradesh murders constituted 1123 of total violent crimes among which none committed homicide by reason of mental illness. ${ }^{2}$

It is a common finding in literature that violence and psychopathology are interrelated. Persons with mental illness can present with high violent behavior and on the other hand criminals can have co morbid psychopathology. In many instances it is very difficult to discern whether the violent behavior is due to psychopathology or criminality. In this context, it is necessary to understand the common characteristics of violent offenders through which we can fairly analyze the factors responsible for violent criminal behavior and whether psychopathology is contributing to the same. By studying the characteristics we can create a criminal profile which can predict recidivism in violent offenders. To identify mental health needs and ensure appropriate care for the mentally ill offenders can be challenging. Proper diagnosis and timely intervention of the mental health problems including substance related disorders may help in the reduction of occurrence or repetition of some offences.

A study conducted on 23 violent offenders at Lund University, Sweden to analyze offender characteristics found that they were often single, most of them had no psychiatric diagnoses, the most frequent modus operandi was a knife or sharp weapon, and the most common homicide typology was domestic disputes, and disputes between friends or acquaintances. Based on analysis, two profiles emerged in the study, one with so-called traditional criminals and another profile over-represented with offenders who commit domestic crimes. ${ }^{3}$

It was found that male sex, cigarette use, alcohol or other drug use, mental health problems, lacking religious belief/practice, low family income, large family (many siblings), and family or friends involved in crime were risk factors. All of these risk factors have been found in numerous studies in high-income countries. ${ }^{4}$

Fazel et al had conducted 62 surveys from 12 countries which included 22790 prisoners, conducted on the entire prison population. Among men, 3.7\% had psychotic illnesses, $10 \%$ major depression, and $65 \%$ a personality disorder, including $47 \%$ with antisocial personality disorder. Among women $4.0 \%$ had psychotic illnesses, $12 \%$ major 
depression, and $42 \%$ a personality disorder, including $21 \%$ with antisocial personality disorder. Which concluded that the prisoners were several times more likely to have psychosis and major depression, and about ten times more likely to have antisocial personality disorder, than the general population $^{5}$ Another study directed specifically towards homicidal offenders, $80 \%$ of the study population was found to be having had axis 1 or axis 2 diagnoses. ${ }^{6}$

Another study showing high prevalence of mental health problems among the prisoners reported substance use disorders as the most common mental disorder among prisoners. Substance use disorders and anti-social personality disorders were significantly higher in male participants. ${ }^{7}$ Similar findings were reported by many other studies. ${ }^{8,9}$ However, some studies report a lower prevalence of $34 \%$ of substance use disorders when compared to other studies. ${ }^{10,11}$

In Indian context, a study done to identify Psychiatric morbidity in prisoners in the entire prison population showed that the prevalence of psychiatric disorders was 33\%. Psychotic, depressive, and anxiety disorders were seen in $6.7 \%, 16.1 \%$, and $8.5 \%$ prisoners respectively. $58.8 \%$ had history of drug abuse/dependence prior to imprisonment. ${ }^{12}$ Another study done only on convict prisoners by Sandeep kumar Goyal found that $23.8 \%$ of the convicted prisoners were suffering from psychiatric illness excluding substance abuse. ${ }^{13}$ This low rate could be due to the exclusion of Substance use disorders from the psychiatric diagnoses.

Even though there are many Indian and foreign studies which focussed on psychopathology and personality of the entire prison population there are a very few Indian studies which specifically focussed on common characteristics and psychopathology in this specific population of violent offenders. Hence the need for the present study.

\section{Aims and Objectives}

To study the various socio-demographic factors, crime characteristics and psychiatric morbidity in violent offenders.

\section{Materials and Methods}

Study was a cross sectional study done for a duration of 3 months from March - May 2018 done at the central prison, Hyderabad, Telangana.

Inclusion Criteria: Males more than 18 years of age convicted for violent crimes like murder (IPC-302) attempted murder (IPC 307), robbery (IPC- 383-385), dacoity (IPC 390395) and rape (IPC 376) who gave consent for the study.

Exclusion Criteria: Males below 18 years of age with serious medical illnesses, deaf and dumb and who did not give consent to participate in study were excluded from the study.

Materials: The scales used in the study were the Semistructured intake proforma, The Mini-International Neuropsychiatric Interview (MINI) International Classification of Diseases (ICD-10).

The M.I.N.I. was designed as a brief structured interview for the major Axis I psychiatric disorders in DSM-IV and ICD-10. Validation and reliability studies have been done comparing the M.I.N.I. to the SCID-P and the CIDI. The results of these studies show that the M.I.N.I. has acceptably high validation and reliability scores, but can be administered in a much shorter period of time (mean $18.7 \pm 11.6$ min., median $15 \mathrm{~min}$.) than the above referenced instruments. It can be used by clinicians, after a brief training session. ${ }^{15}$

Procedure: The study was conducted at the Central Prison, Hyderabad, Telangana. This prison caters to offenders of the entire Telangana state. Permission from DIG, prisons department was taken to carry out the study in the months of March- May 2018. The subjects were included in the study after taking oral informed consent. 65 violent CT offenders involved in crimes like murder (IPC SEC 302) and attempt to murder (IPC SEC 307) dacoity, rape, robbery, abetment to suicide etc, were selected by using convenient sampling method. The various characteristics of offenders like sociodemographic profile, substance use, crime characteristics like homicide typology and victim characteristics were taken using a semi structured intake proforma and past psychiatric illnesses was diagnosed using ICD-10 criteria. Current Psychopathology and Anti-social personality disorder were analysed using MINI scale. ${ }^{14}$ There were 5 drop outs as they were unable to fully complete the intake proforma and so had to be removed from the study.

\section{Statistical Analysis}

Descriptive statistics were done using software SPSS 21 version and depicted using frequency tables, bar diagrams, pie charts.

\section{Results and Discussion}

Our present sample comprised of prisoners who committed, Murder (IPC-302), Attemptive murder (IPC307), Dacoity (IPC 390-395), Rape (IPC 376) and only one person was a serial killer.

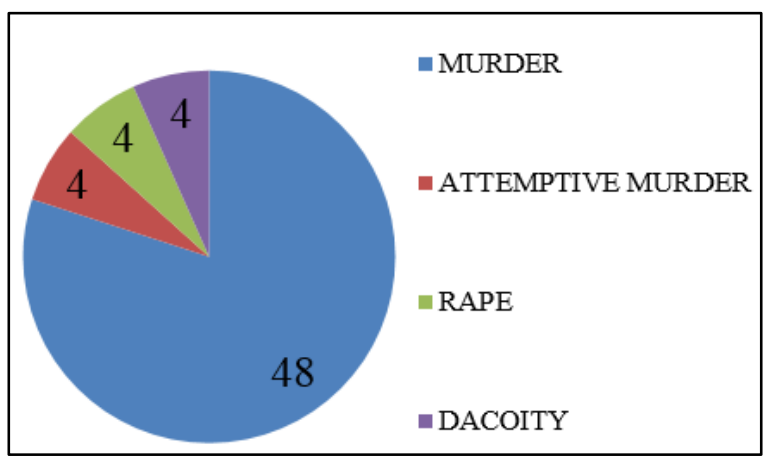

Fig. 1

In our sample $80 \%$ were undergoing life imprisonment and for majority $(63.3 \%)$ the duration of stay in prison is $1-5$ years. On analysis of socio demographic profile it was found that majority of the offenders (43.3\%) belong to 26-35 years and $63.3 \%$ of them were married, $53.3 \%$ belonged to rural background, majority (55\%) belonged to low SES. Similar findings of association between low SES and violent offences was found in many studies. ${ }^{3,4,15,16}$ Also in our study $63 \%$ of them were married and living with family members. But in a study done by Kushnood et $\mathrm{al}^{3}$ on 23 violent offender 16 were 
single at the time of the crime, (and 3 of the them were minors when the crime was committed) four were "separated/divorced" and three were married. The difference may be due to sample size discrepancy.

\section{Education}

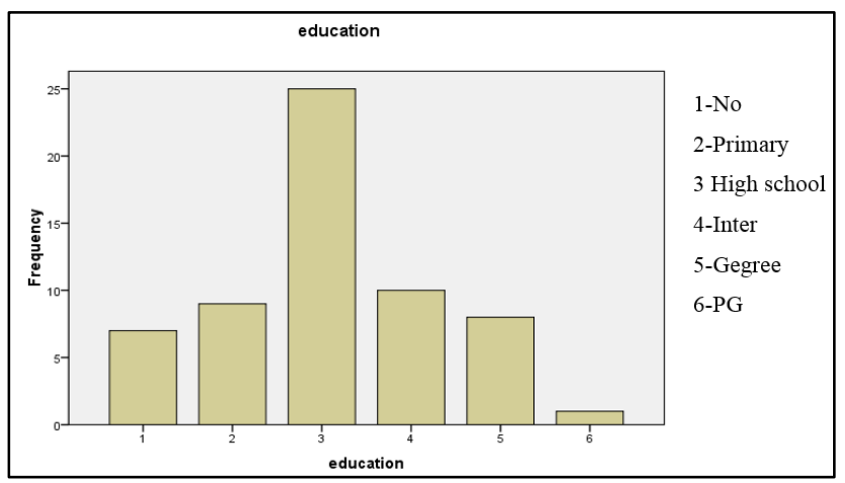

Fig. 2

In our study (25\%) of the offenders studied till high school but majority were unskilled $(45 \%)$ and semiskilled labourers $(38.3 \%)$. Also low education, unemployment and low income increases risk of violence according to Mikko alatonen which is in line with our study. ${ }^{15}$

\section{Employment}

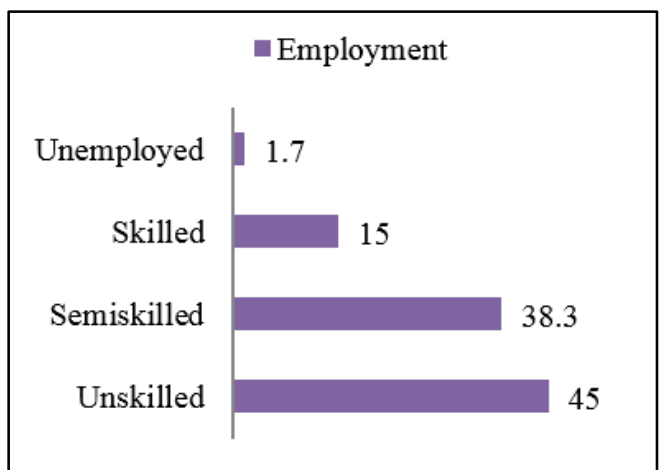

Fig. 3

Crime Characteristics: Only $3.3 \%$ had prior convictions and crime record and, none had family history of crime. Similar findings were found in a study conducted by Mikko alatonen 2012 which showed offenders to have least prior convictions and prison sentences. ${ }^{15} 70 \%$ of the crime occurred due to domestic causes, $63.3 \%$ in private places (most common at victim/offenders home) ${ }^{2}$ and $46.7 \%$ reported intoxication at time of crime. ${ }^{4}$ Perpetration of the crime due to the victims were reported by $38.3 \%$ whereas impulsive, accidental crimes contributed to majority $36.7 \%$, $45.0 \%$ respectively. Only 10 subjects reported that their crime was pre-planned.

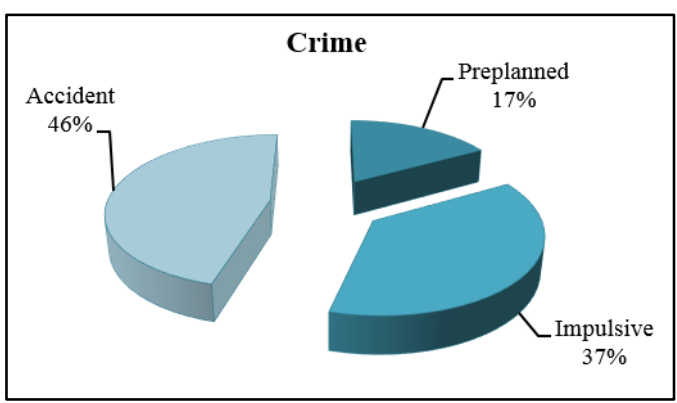

Fig. 4

Victim Characteristics: Most of the victims were females $(61.7 \%), 60 \%$ of them were family members of the offender, spouse in half of the cases. Majority belonged to low and mid socio economic status (SES). Low SES and alcohol dependence syndrome were found to be strong predictors of intimate partner violence in Dobash et al, ${ }^{16}$ study which is in concordance with our study. In our study $5 \%$ had mental illness and 5\% had a criminal background which is an incidental finding in our study and did not influence the crime committed by violent offenders in any way.

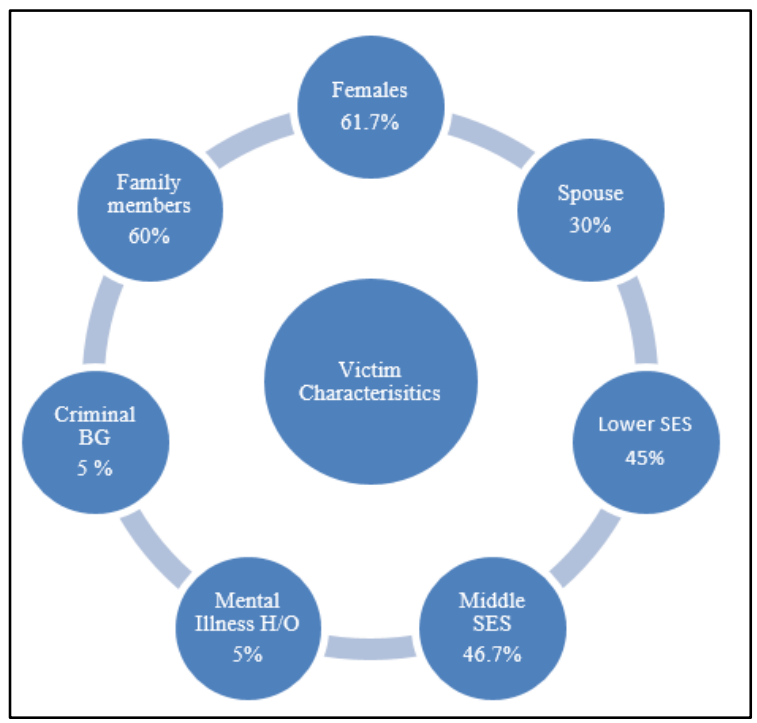

Fig. 5

Psychopathology: In the sample 58.4\% qualified for alcohol dependence syndrome prior to crime and none qualified for any other psychiatric illnesses (other than alcohol dependence syndrome) prior to the crime or at time of commission of crime which was also found in other studies. ${ }^{3,16}$ However, $10 \%$ had adjustment disorder with depressive features which developed during the stay in prison. Only $2(3.3 \%)$ prisoners had antisocial personality traits. Similar findings were found by Kushnood et al which had no significant psychiatric illness ${ }^{3}$ but in another study done by Fazel et al found significant psychopathology in prison population which included both violent and non violent offenders, ${ }^{5}$ where as our study focused on convicted violent offenders only. 


\section{Conclusion}

Although certain characteristics stand out, it is important to note that violent crime is multi-factorial, complex and embraces several theories. With that stated, the purpose of this study was mainly to be able to produce one or more profiles of offenders convicted of murder, attempted murder in Telangana. The common profile which emerged was persons of young age, low education, married, low socio economic status, and rural background, unskilled employed with no criminal background, committed crime under intoxication, perpetuated and impulsive due to domestic reasons. It is remarkable to know that no one had other psychiatric symptoms apart from substance dependence and intoxication at the time of commission of crime.In our study we found $58.4 \%$ subjects with alcohol dependence, and most of the crimes were committed on relatives, mostly spouses. Majority were directly or indirectly due to use of alcohol most probably, since no other psychiatric illness or underlying personality disorders could be diagnosed. (in our study only $3.3 \%$ had antisocial personality traits which is not significant). So more awareness programs and campaigns regarding influence of alcohol on the crimes, can be projected with the help of Police, Government, Private organisations and media, especially in vulnerable and at risk population. This may lead to reduced consumption of alcohol in the vulnerable population leading to a decrease in crime rate.

Strengths and Limitations: In India there are many studies conducted on whole of prison population and their underlying personality but there are few studies which focused only on violent offenders and their characteristics which is specific population. By studying the characteristics we can create a criminal profile which can predict recidivism in violent offenders. Only CT violent offenders were interviewed the limitations were that most of the information was taken from prisoners and there was no means to corroborate the information so there is also a possibility of recall bias. In the prison population some of the subjects refused to take part in the study as they thought that they would be referred to psychiatric hospital if they participated in the study.

Implications: It is a pilot study conducted to understand the basic characteristics of violent offenders but future studies should be aimed at understanding the personality profile and comparative studies with non violent and female offenders should be conducted. Modifiable factors like substance use, psychiatric illnesses can be addressed. By this study we understand that most of them are impulsive so personality traits should be identified which will be carried out in future research.

\section{Acknowledgements}

1. DIG Central prison and Jail Superintendent of Cherlapally for giving us permission to conduct the study.

2. Thanks to - Dr. Shiva Kumar for statistical support, all the prison inmates without which the study could not be conducted.

\section{References}

1. National Research Council study. Violent Crime Richard Rosenfeld Last Reviewed: 26 October 2017 DOI: 10.1093/OBO/9780195396607-0001

2. National Crime Records Bureau 2016, Ministry of Home Affairs GOI.

3. Ardavan Khoshnood \& Marie Väfors Fritz. Offender Characteristics: A Study of 23 Violent Offenders in Sweden Department of Criminology, Malmö University .Published in: Deviant Behavior (2017;38(2):141-153. 2017;38(2):141-53. DOI:10.1080/01639625.2016.1196957.

4. Joseph Murray a, Daniel Ricardo de Castro Cerqueira, Tulio Kahn. Crime and violence in Brazil: Systematic review of time trends, prevalence rates and risk factors. Aggression and Violent Behavior. 2013;18:471-483.

5. Fazel S, Grann M. Psychiatric morbidity among homicide offenders: a Swedish population study. Ame J

Psychiatry. 2004;161(11):2129-2130.

6. Axis I and Axis II diagnostic parameters of homicide. Yarvis RM. Bull Am Acad Psychiatry Law. 1990;18(3):249-270.

7. Anitha Kumari Ayirolimeethal, G. Ragesh, Biju George.Psychiatric morbidity among prisoners. Indian $J$ Psychiatry. 2014;56(2):150-153. doi: 10.4103/00195545.130495

8. L. Birmingham, D. Mason, and D. Grubin. Prevalence of mental disorder in remand prisoners: consecutive case study. BMJ. 1996;313(7071): 1521-4. PMCID: PMC2353026 PMID: 8978227

9. D. Brooke, C. Taylor, J. Gunn, and A. Maden. Point prevalence of mental disorder in unconvicted male prisoners in England and Wales. BMJ. 1996;313(7071):1524-1527. PMCID: PMC2353052 PMID: 8978228.

10. Gunn J, Maden A, Swinton M. Treatment needs of prisoners with psychiatric disorders. BMJ. 1991;303:338-341.

11. Guy E, Platt JJ, Zwerling I, Bullock S. Mental health status of prisoners in an urban jail. Crime Justice Behav. 1985;12:2953.

12. Vinod Kumar and Usha Daria. Psychiatric morbidity in prisoners. Indian J Psychiatry. 2013;55(4):366-370. doi: 10.4103/0019-5545.120562 PMCID: PMC3890918 PMID: 24459308.

13. Goyal SK, Singh P, Gargi PD, Goyal S, Garg A. Psychiatric morbidity in prisoners. Indian J Psychiatry. 2011;53:253-257.

14. http://www.cure4you.dk/960/MINI\%205.0.0\%20English.pdf

15. Mikko Aaltonen, Janne Kivivuori, Pekka Martikainen and Venla Salmi. Socio-Economic Status and criminality as predictors of Male Violence Does Victim's Gender or Place of Occurrence Matter. doi:10.1093/bjc/azs045.BRIT. J. CRIMINOL. (2012) 52, 1192-1211.9 August 2012.

16. Russell P, Dobash R. Emerson dobash. Women's violence to men in intimate relationships. Br J Criminol. 2004;44:324349. Advance Access publication 8 April 2004. 